\title{
Development of PISA Model Mathematical Problems on Space and Shape Content to Measure Problem Solving Ability Middle School Mathematics
}

\author{
Yulia Siska Siahaan ${ }^{1, *}$ Edy Surya ${ }^{2}$ Pargaulan Siagian ${ }^{3}$ \\ ${ }^{1,2,3}$ State University of Medan \\ *Corresponding author. Email: mariamzuli9@gmail.com
}

\begin{abstract}
This study aims to: produce a mathematical problem using the PISA Model on Space and Shape content that is valid and practical to measure the mathematical problem solving ability of junior high school students. This research is a research and development type of formative evaluation Tessmer which consists of two stages, namely; (1) preliminary stage, and (2) formative evaluation stage which includes self-evaluation and prototyping. The prototyping stage consists of expert reviews, one-to-one, small group, and field tests. The subjects of this study were students of class IX-I SMP Swasta Kualuh, totaling 32 students. The results of the study indicate that the PISA Model mathematical problems have been successfully developed on the quality Space and Shape content from the aspects of validity and practicality. Valid based on the results of validation by experts who stated "the questions can be used with a little revision", with a reliability coefficient of 0.716 (high reliability). Practically based on expert judgments, teacher response questionnaires and student response questionnaires. The results of the teacher's response from the six assessment items obtained an average score of $83.33 \%$ is "practical". While the student response of $75 \%$ is "positive" to the questions that have been given by the researcher. Based on the results of data analysis of students' mathematical problem solving abilities, the average is obtained While the student response of 75\% is "positive" to the questions that have been given by the researcher. Based on the results of data analysis of students' mathematical problem solving abilities, the average is obtained While the student response of $75 \%$ is "positive" to the questions that have been given by the researcher. Based on the results of data analysis of students' mathematical problem solving abilities, the average is obtainedscore 49.22. This value indicates that the level of students' mathematical problem solving ability is included in the "medium" category.
\end{abstract}

Keywords: PISA Model Math Problems, Mathematical Problem Solving, Formative Evaluation, Space and Shape.

\section{INTRODUCTION}

Human knowledge of mathematics has an important role in human civilization, so mathematics is a field of study that is always taught at every level of education in schools [1]. Education is training for an individual to improve his insight and skills in order to become a good citizen. Because of the importance of education, the progress of a nation can be seen from the quality of its education. The better the education system in a country, the better the quality of human resources created. One of the fields of study at every level of education in Indonesia is mathematics. Mathematics is often considered the most difficult subject, because students still do not really understand mathematics.[2] mathematics is also referred to as human life because mathematics is a product of human intellectual thinking. Intellectual thinking can be driven from problems involving real everyday life. Mathematics is the key to the chances of success. For a student, the success of studying it will open the door to a brilliant career. For citizens, mathematics will support the right decision making, and for a country, mathematics will prepare its citizens to compete and compete in the economic and technological fields.

The objectives of learning mathematics are: (1) understanding mathematical concepts, explaining the relationship between concepts and applying concepts or algorithms flexibly, accurately, efficiently and consistently in problem solving, (2) using reasoning on patterns and properties, performing mathematical manipulations in making generalizations, compiling 
evidence or explaining mathematical ideas and solutions, (3) solving problems which include the ability to understand problems, design mathematical models, complete models and find solutions, (4) communicate mathematical ideas with symbols, diagrams or other media to clarify the situation or problem, ( 5) have an attitude of appreciating the usefulness of mathematics in life, namely having a sense of curiosity, knowing attention and interest in learning mathematics as well as a tenacious and confident attitude in problem solving [3].

This is also in accordance with the objectives of the 2013 curriculum, which is to prepare Indonesian people to have the ability to live as individuals and citizens who are faithful, productive, creative, innovative, and affective and able to contribute to the life of society, nation, state, and world civilization [4]. By examining the objectives of learning mathematics, of course it is logical if mathematics becomes a compulsory subject at the primary and secondary levels in all existing educational units. With the mathematics learning process and good achievements in it, of course the quality of Indonesian human resources will be raised so that an intelligent, open, peaceful, and democratic life will be realized.

However, the reality on the ground shows that it seems that these goals have not yet been fully achieved. Based on the PISA results obtained by Indonesian students, it is alarming that in 2000 Indonesia was ranked 39 th out of 41 countries, then in 2003 Indonesia was ranked 38th out of 40 countries. Indonesia experienced a decline in 2006 which was in the 50th position out of 57 countries. In 2009 Indonesia's position continued to decline, namely at position 61 of 65 countries. The next period, namely in 2012, Indonesia's ranking continued to experience a drastic decline, namely 64 out of 65 countries. Indonesia has increased which is in position 62 of 70 countries in 2015 [5], then in 2018 Indonesia again declined compared to 2015 which was in position 74 out of 79 countries [6] From the results of the PISA survey above, it shows that Indonesian students are almost always ranked last in the world. These results successively occur during the test. This shows that Indonesian students have low problem solving abilities. PISA (Program for International Student Assessment) is one of the international level assessments that is held every three years with the aim of knowing the ability of students to solve everyday problems whose questions are questions based on real situation problems with an assessment focus on process mastery, understanding concepts, and the ability to apply them. PISA (The Program for Internationale Student Assessment) is the study of international student assessment programs organized by the Organization for Economic Cooperation and Development (OECD).

PISA is designed to find out whether students can use their mathematical potential in real life in society through a contextual mathematical learning concept. Wardhani
(2005) suggests that PISA questions are very demanding on reasoning and problem-solving abilities. In his study, Pisa tested students using tests. In the PISA questions, there are eight characteristics of mathematical cognitive abilities, namely, communication, mathematising, representation, reasoning and argument definition, strategies for solving problems, using symbolic, formal and technical language and operations, using mathematics tools [7].

In the PISA domain, four contents were developed which include Change and Relationship, Shape and Space, Quantity, and Uncertainty and Data. Several studies on the development of PISA questions that have been carried out include the title Development of PISA Model Questions on Change and Relationship Content to Determine the Mathematical Reasoning Ability of Junior High School Students [8]. Research by Mulia Putra and Rita Novita (2015) with the title "Profile Of Secondary School Students With High Mathematics Ability in Solving Shape and Space Problems" [9].

Space and Shape Content is one of the contents in the assessment of mathematical literacy related to threedimensional material that is focused on how to determine the position of points, lines and planes in threedimensional space. The criteria and indicators that will be achieved in this material are determining the distance from point to point, point to line and point to plane, as well as determining the distance from line to line in three dimensions. Geometry is concerned with spatial relations which studies form, space, composition and its properties, sizes and relationships between one another. In geometry, students need relatively high visual abilities. For example, when students are faced with the problem of finding the length of the line that connects the midpoints of the 2 diagonals of a square, that's when the students are required to imagine a real wake to be able to solve the problem. In this case, it is not only a problem of visualization ability but also students' understanding of ribs and skeletons.According to Johar [10], one of the things that can be done to overcome this is to familiarize students with practicing PISA model questions. This habituation can be started from learning in class. Therefore, it is necessary to develop questions equivalent to PISA with the Indonesian context either by teachers, researchers, or students who are completing their final assignments. This is in line with the results of researcher interviewswith a teacher in the field of mathematics, namely Mr. Amri Makmur said that The problem faced by mathematics teachers at Kualuh Labura Private Junior High School is that students generally have low mathematical problem solving abilities. Especially for students who are basically less interested in learning mathematics, these students naturally lack the desire to really study mathematics and do not try to improve their abilities.in the learning process takes place, the teacher explains the lesson and students listen to what is explained by the teacher, but when the teacher asks for a 
response or response from students (feedback) what happens is that most students are silent, few respond, so the learning process is passive. When the teacher gives an example, students understand right away but when given a slightly different task or question, students find it difficult and often ask for the opinion of friends who they think are smarter and in the end students prefer to copy the work of their friends rather than find their own answers. In a study conducted by Babys (2016) inIn the nature of learning and activities in the classroom, students are more waiting for orders and directions from the teacher so that if the teacher is less motivated, students are more passive. Students are accustomed to learning to receive information directly from the teacher without finding it themselves, lack of developing ideas and ideas, accustomed to working on problems in the form of symbols and numbers so that when given questions in the form of stories and related to the real world, students have difficulty interpreting them in mathematical form. Students in Indonesianeed to get used to solving PISA problems. However, in Indonesia, contextual questions are not available in everyday life which are designed to hone students' problem solving skills and have the characteristics and framework of PISA questions. From these problems, it is necessary to develop valid PISA math problems. Valid based on the assessment of the validator according to the PISA standard criteria and the language according to the EYD. To develop valid PISA math problems on space and shape content for junior high school students, a development model is needed that researchers use in data collection. The concepts in the PISA model problems relate mathematics to everyday life, which is in accordance with the current 2013 curriculum and the PISA model math problems contain eight cognitive abilities, including thinking and reasoning, argumentation, communication, modeling, problem possing and solving, presentation, use of symbols, formal and technical language. and operations, and use of assistive devices. The eight cognitive abilities of mathematics are also in accordance with the objectives of learning mathematics contained in the 2013 curriculum, especially problem solving abilities.

In line with the opinion of Saragih \& Napitupulu (2015), that: "The students are expected to use mathematics and mathematical mindset in daily life, and to study many kinds of sciences which stress to logical arrangement and student's character building and also ability to apply mathematics" That the meaning is that students are expected to use mathematics and mathematical thinking patterns in everyday life, and learn various types of science that emphasize logical rules and also the ability to apply mathematics. In other words, students are expected to be able to achieve High Order Thinking Ability or Higher Order Thinking Skills (HOTS) [11].
One of the high-level abilities studied by researchers is the ability to solve mathematical problems. This problem-solving ability is one of the objectives of learning mathematics, namely solving problems which include the ability to understand problems, design mathematical models, complete models and interpret solutions obtained.Problem solving ability is a very important part of the curriculum of mathematics because in the learning process and its completion, students have the potential to gain experience using the knowledge and skills they already have to be applied to non-routine problem solving.

The importance of problem solving is expressed by Beigie by stating that through problem solving, students can learn about deepening their understanding of mathematical concepts by working through selected issues using the application of mathematics to real problems. The development of mathematical problem solving abilities can equip students to think logically, analytically, systematically, critically, and creatively [12].

As Vettleson said that in the discipline of mathematics, the use of problem solving skills is very important and very influential. Problem solving is the basis of all mathematical and scientific discoveries [13].

From the opinions above, it is natural that problem solving abilities should receive special attention, seeing their very strategic role in developing students' intellectual potential. Problem solving skills are very important for students to have, because they can improve the way students learnthink, like; think logically, analytically, systematically, critically, and creatively.

From the facts above, it can be seen that it takes a development of questions that can provide space for students to be able to better practice their problem solving skills. In the PISA questions, the focus is on the ability of students to use their skills and knowledge in dealing with real-life challenges. This orientation then reflects a change in curriculum goals and objectives whose development relates to what students can do with what they have learned in school and not just about whether they have mastered certain curricular content. Based on the background described above, the writer is interested in conducting a research entitled Development of PISA Model Problems on Space and Shape Content to Measure Problem Solving Ability of Junior High School Students which is valid and practical.

\section{LITERATURE REVIEW}

\subsection{Mathematical Problem Solving Review}

In general, the definition of ability according to the $\mathrm{KBBI}$ (Big Indonesian Dictionary) is a person's ability to do something. A person is said to have the ability if he can and is able to do something that really has to be done. 
Ability is the power (strength) to perform an action. Abilities can also be innate abilities, or they can be the result of practice or practice. From this understanding, it can be concluded that ability is the ability to do something.

Problem solving has two syllables, namely problem and solution. So that in understanding what is meant by problem solving, the following will discuss the two syllables that build it. What's the problem? According to Duncker, the problem arises when a person has a goal but does not know how to achieve it [14]. According to Lester, a job is a problem for someone if he is interested in completing the job, but does not yet have a procedure that can be applied directly to complete it. Meanwhile, according to Jonnasen, a problem is something (entity) that is not yet known, and if it is found it will have social, cultural, or intellectual value. Problems usually contain a situation that encourages someone to solve it, but do not know directly what to do to solve it. If a problem is given to a child and the child immediately knows how to solve it correctly, then the problem cannot be said to be a problem for the child [2].

According to Polya, problem solving is an attempt to find a way out of a difficulty in order to achieve a goal that cannot be achieved immediately. According to Sternberg and Been Zeev problem solving is a cognitive process that opens problem solving opportunities to move from a state of not knowing how to solve it to a state but not knowing how to solve it [2]. From some opinions of experts, it can be concluded that mathematical problem solving is an attempt to find a solution to a mathematical problem by combining mathematical concepts and rules that have been obtained previously to achieve the desired goal.

Based on the description above, it can be concluded that mathematical problem solving ability is the ability to overcome mathematical difficulties by combining mathematical concepts and rules that have been obtained previously to achieve the desired goal. To be able to solve mathematical problems well, appropriate steps or problem-solving strategies are needed.

According to Polya, developing problem solving models, procedures, or heuristics which are grouped into stages of problem solving, namely:

1. Understanding the problem (understanding the problem)

2. Planning a solution (devising a plan)

3. Implement a problem-solving plan (carrying out the plan).

4. Re-checking the correctness of the settlement (looking book)

The indicators for measuring mathematical problem solving ability according to the NCTM are as follows:
1. Identify the elements that are known, which are asked, and the adequacy of the elements needed,

2. Formulate mathematical problems or develop mathematical models,

3. Applying strategies to solve various problems (new types and problems) inside or outside mathematics

4. Explain the results according to the problem, and

5. Use math meaningfully

From the problem solving indicators above, Charles, Lester, and O'Daffer (in Szeteladan Nicol, 1882: 2) develop indicators of each aspect or stage of problem solving: (1) Understanding the Problem (Understanding Problem), (2) Planning Problem Solving (Solving the Problem), and (3) Solving the Problem (Answer the Problem), Szetela and Nicol (1882) said that aspects and indicators modified by Charles, Lester, and O 'The Daffer from NCTM is easy for teachers to use to measure and analyze students' mathematical problem solving abilities.

From the aspects, indicators, and emphasis of each of the indicators above are used as scoring guidelines in this study to analyze students' mathematical problem solving abilities. So, from the description above, it can be concluded that the students' mathematical problem solving ability is the ability of students to solve math problems by paying attention to the process of finding answers based on the stages of problem solving, namely (1) Understanding the Problem (Understanding Problem), (2) Planning Problem Solving (Solving the Problem), and (3) Solving the Problem (Answer the Problem).

\subsection{PISA (Program for International Student Assessment)}

PISA (Program for International Student Assessment) is an international study organized by the OECD (Organization for Economic Corporation and Development) made in 1997 , is a commitment by the governments of OECD countries to monitor the results of the education system in terms of student achievement within an internationally agreed framework. PISA is a collaborative effort, bringing together the scientific expertise of participating countries and jointly controlled by their governments on the basis of policy-driven common interests. PISA examines the literacy ability of students in the age range of 15-16 years which is followed by several participating countries, including Indonesia. Measured ability in PISA is the ability of knowledge and skills in three cognitive domains, namely reading, mathematics, and natural sciences. The measured abilities are tiered from the lowest level of difficulty to the more difficult level. The questions that must be answered in the multiple choice form start from choosing one simple alternative answer, such as answering yes/no, to a rather complex alternative answer, 
such as responding to several choices presented. On questions that require descriptive answers, students are asked to answer with short answers in the form of words or phrases, then rather long answers in the form of descriptions that are limited in the number of sentences, and answers in the form of open descriptions [8].

Framework (framework)development of PISA questions that measure mathematical ability using the term literacy. OECD (2013:25) defines mathematical literacy as follows.

"Mathematical literacy is an individual's capacity to formulate, employ, and interpret mathematics in a variety of contexts. It includes reasoning mathematically and using mathematical concepts, procedures, facts and tools to describe, explain and predict phenomena. It assists individuals to recognize the role that mathematics plays in the world and to make the well-founded judgments and decisions needed by constructive, engaged and reflective citizens".

Based on the definition of literacy, the focus of the PISA assessment is the accumulation of mathematical knowledge of 15 year olds that can be used in various conditions and reflects the process of formulation, application of concepts and interpretation of solutions to problems. The literacy concept focuses on students' capacity to apply mathematical knowledge and skills as well as the ability to analyze, reason and communicate (such as proposing, solving and interpreting problems) effectively in various situations in life. On the one hand, everyday human life requires mathematical literacy with different levels based on work and the surrounding environment [14]. Stacey (2011) explains that mathematical literacy is not only described as a basic level of ability used in simple mathematical activities such as shopping, but also the ability to use mathematics in the world of work at a more difficult level. Therefore, mathematical literacy includes a variety of low-level thinking skills, but also higher- order thinking skills. PISA becomes very important because students have to relate their mathematical knowledge to practical situations or problems encountered in everyday life [15]. PISA is designed to find out whether students can use their mathematical potential in real life in society through a contextual mathematical learning concept.

In PISA there are three characteristics that are the main components in PISA questions, namely:

1. The content used to assess students' ability to solve real problems (student's capacity to solve real problems), namely: change and relationship (Change and Relationship), space and shape (Space and Shape), quantity (Quantity), and uncertainty and data (Uncertainty and Data).

2. Context is a question item that is specifically set from the situation in the selection of strategies and representations that are suitable for solving problems, namely: personal (personal), occupational (occupational), social/general (societal), and scientific (scientific).

3. Competency group is a process that students do to connect a problem with mathematics in problem solving, namely: reproduction, connection, reflection

\subsubsection{Space and Shape Content}

Space and shape (Space and Shape), includes phenomena related to the visual world (visual world) involving patterns, properties of objects, position and orientation, representation of objects, coding of visual information, navigation, and dynamic interactions related to shapes. real.Geometry serves as an important foundation for space and form, but the category goes beyond traditional geometry in terms of content, meaning and method, drawing on elements of other areas of mathematics such as spatial visualization, measurement, and algebra. For example, shape changes, and a point can move along the locus, thus requiring the concept of function. Measurement formulas are very important in this field. The manipulation and interpretation of shapes in settings requiring tools ranging from dynamic geometry software to Global Positioning System (GPS) software fall into this content category. Technology allows students to integrate geometric knowledge with visual information to build accurate mental models. For example, to find the volume of a cup, one can manipulate an image to identify that it is a truncated cone, to identify a perpendicular height and where it can be measured, and to ascertain that what might look like ellipses at the top and bottom in a two-dimensional image is actually a circle in three-dimensional space. In conclusion, here is a list of the key aspects of space and form: recognizing shapes and patterns, describing, encoding and decoding visual information, understanding dynamic changes to form similarities and differences in relative positions; 2 $\mathrm{D}$ and 3-D representations and the relationships between them, navigation through space.

\subsubsection{PISA Troubleshooting Framework (Problem Solving Framework)}

Problem solving is an additional assessment in PISA 2003. The purpose of the PISA problem solving assessment is to assess an individual's problem solving competence.

The PISA definition of problem solving competence is based on the generally accepted meanings of "problem" and "problem solving" as follows:

Problem-solving competency is an individual's capacity to engage in cognitive processing to understand and resolve problem situations where a method of solution is not immediately obvious. It includes the willingness to engage with such situations in order to 
achieve one's potential as a constructive and reflective citizen.

Not surprisingly, the first sentence of this definition is almost identical to the first part of the definition used for the 2003 PISA problem solving assessment. However, the 2003 definition has only a cognitive dimension, with the last section highlighting the crosscurriculum nature of assessment, an affective component having been introduced in the 2012 definition. in line with the definition of competence as recognized by the OECD, 2003a. What distinguishes the 2012 problemsolving assessment from the 2003 assessment is not the definition of problem-solving competence, but the way in which the 2012 assessment (computer-based) is delivered and the inclusion of problems that cannot be solved without the problem solver interacting with the problem situation. The things that are very important for the PISA problem solving assessment are 1) The context of the problem, whether it involves technology or not, and whether the focus of the problem is personal or social. 2) The nature of the problem situation, whether interactive or static. 3) The problem solving process, the cognitive process involved in solving the problem.

\section{RESEARCH METHODS}

This development research was carried out to produce PISA Model math problems on Space and Shape content to measure the mathematical problem solving abilities of junior high school students to be tested in class. This research was carried out at the Kualuh private junior high school class IX. This research will be carried out in the even semester of the 2020/2021 academic year on the subject of Constructing Curved Side Space (BRSL). The reason for choosing this research location is because similar research has never been carried out at the school. The subjects in this study were 32 students of class IX SMP Private Kualuh for the academic year 2020/2021, and the object of this study was the development of PISA model math problems with shape and space content. This research will be carried out in the even semester of the 2020/2021 academic year on the subject of Constructing Curved Side Space (BRSL). The reason for choosing this research location is because similar research has never been carried out at the school. The subjects in this study were 32 students of class IX SMP Private Kualuh for the academic year 2020/2021, and the object of this study was the development of PISA model math problems with shape and space content. This research will be carried out in the even semester of the 2020/2021 academic year on the subject of Constructing Curved Side Space (BRSL). The reason for choosing this research location is because similar research has never been carried out at the school. The subjects in this study were 32 students of class IX SMP Private Kualuh for the academic year 2020/2021, and the object of this study was the development of PISA model math problems with shape and space content.
Schematically, the procedure for developing mathematical problems using the PISA model is as follows:

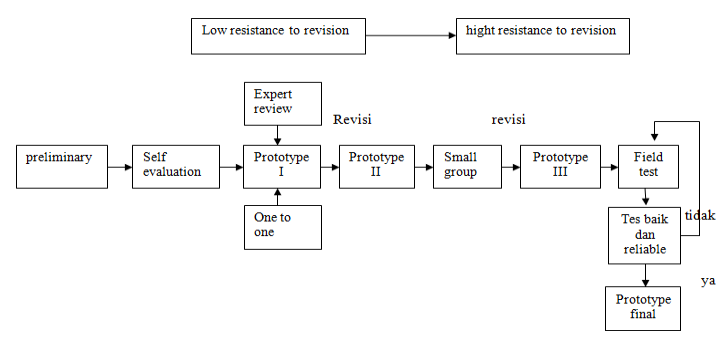

Figure 1. The PISA Model Mathematical Problem Development Procedure

\section{RESULT AN DISCUSSION}

In the development of the PISA model math problems on the Space and shape content to measure the mathematical problem solving abilities of junior high school students in this study, the stages of the Tessmer development model were followed. The Tessmer development model consists of two stages, namely; (1) preliminary stage, and (2) formative evaluation stage which includes self-evaluation and prototyping. The prototyping stage consists of expert reviews, one-to-one, small group, and field tests.

Based on the formulation of the problem posed in chapter I, the results of the data analysis obtained from the results of the one-to-one, small group, and field test trials indicate that the PISA model math problems with space and shape content to measure students' mathematical problem solving abilities are valid and practical. The development process that is passed consists of two stages, namely; (1) the preliminary stage, and (2) the formative evaluation stage which includes self-evaluation, prototyping (expert reviews, one-to-one, and small group), as well as field tests and revisions at each stage that produce a product. The product produced in the development of this problem is a PISA model with space and shape content to measure students' mathematical problem solving abilities. The questions developed can be categorized as valid and practical. The question was declared valid after going through a validation process from several validators who contributed in the form of suggestions and comments to improve the question both in terms of content, construct and language. This is in accordance with Suherman's opinion which states that theoretical validity or logical validity is the validity of an instrument based on theoretical or logical considerations. An evaluation tool is considered based on theoretical validity which is studied or considered by the evaluator. In order for the results of these considerations to be adequate, it should be carried out by experts or people who are considered experts for that, at least people who are experienced in their fields [17]. It can be interpreted that if the question is considered good by the validator then the question can be categorized as valid according to theoretical validity. 
Further revisions were made to prototype I based on suggestions/comments from expert reviews and one-toone student answers. The revised questions based on expert reviews and one-to-one were called prototype II. These questions were tested in a small group consisting of 6 students in class IX-2 at a private junior high school in Kualuh. At this stage, the researcher only acts as an observer and students are asked to work on all the available questions and then provide suggestions and comments on the questions that have been done. Furthermore, based on the results of item analysis and student comments/suggestions in this small group, prototype III consisting of 5 questions was maintained and tested on the field test. The questions that have been revised based on expert reviews and one-to-one are called prototype II. These questions were tested in a small group consisting of 6 students in class IX-2 at a private junior high school in Kualuh. At this stage, the researcher only acts as an observer and students are asked to work on all the available questions and then provide suggestions and comments on the questions that have been done. Furthermore, based on the results of the analysis of the questions and comments/suggestions of students in this small group, prototype III consisting of 5 questions was maintained and tested on the field test. The questions that have been revised based on expert reviews and one- toone are called prototype II. These questions were tested in a small group consisting of 6 students in class IX-2 at a private junior high school in Kualuh. At this stage, the researcher only acts as an observer and students are asked to work on all the available questions and then provide suggestions and comments on the questions that have been done. Furthermore, based on the results of the analysis of the questions and comments/suggestions of students in this small group, prototype III consisting of 5 questions was maintained and tested on the field test. The researcher only acts as an observer and students are asked to work on all the questions that are available then provide suggestions and comments on the questions that have been done. Furthermore, based on the results of the analysis of the questions and comments/suggestions of students in this small group, prototype III consisting of 5 questions was maintained and tested on the field test. The researcher only acts as an observer and students are asked to work on all the questions that are available then provide suggestions and comments on the questions that have been done. Furthermore, based on the results of the analysis of the questions and comments/suggestions of students in this small group, prototype III consisting of 5 questions was maintained and tested on the field test. At the field test stage, the PISA model math questions to measure students' mathematical problem solving abilities in prototype III were tested on the research subject, namely class IX-1 students of Kualuh private junior high school, totaling 32 students on February 15, 2021. These questions given to students for 2 hours of lessons (180 minutes) carried out for one day. Each student is given an answer sheet and collected according to the time given.
During the process of working on the questions, the researcher observed and interacted with the students to see the difficulties that might occur so that they could find out the students' problems in answering the questions.

Based on the results of the analysis of the field test stage, 5 valid questions were obtained with a reliability coefficient of 0.716 (high reliability). For the results of the discriminatory test, the 5 questions that were tested at the field test trial stage had discriminatory power in the "enough" category for questions number 1 , and 3, while for questions number 2, 4, and 5, they had distinguishing power in the "good" category. . While the results of the difficulty level at the field test trial stage for questions number 2, and 3 have a difficulty level in the "Medium" category, for questions number 1,4 and 5 have a difficulty level in the "Difficult" category, it can be concluded that the PISA model math problems the space and shape content to measure students' mathematical problem solving abilities that have been developed is valid qualitatively and quantitatively.In line with the question development research conducted by Charmila, Zulkardi \& Darmawijoyo (2016), it was shown that this study produced 14 questions in the Jambi context that were valid, practical, and had potential effects. Valid in terms of content, construct, and language based on the validator's assessment [10].

As explained in chapter II, the product developed can be said to be practical if it meets the following criteria: (1) Experts state that the development of the developed questions can be applied. (2) In real terms in the field, teachers and students as users stated that the development of the developed questions could be applied by Nieeven [18]. The product developed in this study is a mathematical problem using the PISA model of space and shape content to measure students' mathematical problem solving abilities and a measuring instrument to measure the practicality of the product developed in this study is a student response questionnaire.

Based on the results of the validation carried out by expert reviews, and the results of student responses with revisions based on comments/suggestions in the one-toone stage of the trial, and small group evaluations showing questions that were developed practically. The questions are categorized as practical, as illustrated by the results of observations in small group trials, where all students can use the set of questions well. The questions developed are in accordance with the student's flow of thought, are easy to read, and do not cause various interpretations. During the field test phase, the questions given were valid and practical questions. The questions given to students consist of 5 questions. Prior to carrying out the test, The researcher provides direction on the procedures for carrying out the test and facilitates students with a set of questions with answer sheets that will be collected at the end of the test time. The teacher's 
response questionnaire and the student's response questionnaire were used as a tool to measure the practicality of math problems in the PISA model of space and shape content to measure students' mathematical problem solving abilities. Based on the results of the teacher's questionnaire, the teacher gave a positive response to the questions that had been given by $83.33 \%$, while those who gave a negative response to the questions that had been given were $16.67 \%$. If this analysis is referred to the criteria set in chapter III, it is concluded that the teacher's response to the practicality of the PISA model of space and shape content to measure students' mathematical problem solving abilities is "very practical". For the results of the student response questionnaire at the one-to-one trial stage students gave a positive response to the questions that had been given by $60 \%$, while those who gave negative responses to the questions that had been given were $40 \%$. In the small group trial stage, students gave a positive response to the questions that had been given by $70 \%$, while those who gave a negative response to the questions that had been given were $30 \%$. and in the field test trial stage, students gave a positive response to the questions that had been given by $75 \%$, while those who gave negative responses to the questions that had been given were $25 \%$. If this analysis is referred to the criteria set out in chapter III, The results of the research above are supported by research conducted by Jurnaidi and Zulkardi show that this research has produced a product of PISA model math problems on change and relationship content to determine the valid and practical mathematical reasoning abilities of junior high school students. Valid depicted fromthe results of the validator's assessment which stated that the questions were good in content, construct, and language. In addition, the validity of the questions is also reflected in the results of the item analysis on students who are not research subjects. Practically illustrated by the results of trials in small groups where most students can understand the questions well [8].

Mathematical problems of the PISA model with space and shape content to measure students' mathematical problem solving abilities that have been categorized as valid and practical, then tested on research subjects totaling 32 students of class IX-1 of Kualuh private junior high school. In the implementation of the field test, the researcher analyzed the students' mathematical problem solving abilities as seen from the students' answers in solving the problems given. Based on the analysis of students' answers to 5 math problems in the PISA model of space and shape content, it can be seen that in solving these questions, some students have shown good indicators of students' mathematical problem solving abilities, namely: (1) Understanding Problems, (2) Planning Problem Solving, (3) Troubleshooting. There are some students who are able to understand the problem but still have difficulty in determining the problemsolving planning strategy. In general, students who are unable to do so are due to errors in understanding the concepts of the questions given by the researcher. In addition, there are still some students who are not used to answering questions that have characteristics such as PISA questions, therefore solving just one question can take a long time. However, if given a question according to the procedural formula given by the teacher, students in this class can solve it in a not too long time. there are still some students who are not used to answering questions that have characteristics such as PISA questions, therefore solving just one question can take a long time. However, if given questions according to the procedural formula given by the teacher, students in this class can solve them in a not too long time. there are still some students who are not used to answering questions that have characteristics such as PISA questions, therefore solving just one question can take a long time. However, if given a question according to the procedural formula given by the teacher, students in this class can solve it in a not too long time.

Based on data analysis at the field test stage to measure students' mathematical problem solving abilities, it is known that of the 32 test subject students there are 2 students who have a "very high" level of problem solving ability with a percentage of $6.25 \%$, there are 7 students who have a high level of problem solving skills. problem-solving ability in the "high" category with a percentage of $21.875 \%$, there are 14 students who have a problem-solving ability level in the "medium" category with a percentage of $43.75 \%$, and there are 9 students who have a problem-solving ability in the "low" category with the percentage of $28.125 \%$ is low. So that the average mathematical problem solving ability of students is 49.22 with"medium" category. This shows that the use of tests in the form of mathematical problems using the PISA model of space and shape content developed has a good impact on students' mathematical problem solving abilities. The results of this study are in line with Aisyah [19] who stated that the results of the PISA type test questions as a whole were included in the sufficient category with an average value of 54.28.

The mathematical problem solving ability of the above students is influenced by the characteristics of the developed PISA model of the mathematical problem test. Among them are: first, the developed test contains authentic problems related to students' daily lives, is clear, easy to understand and useful. Second, the activities designed on the test are in accordance with the students' mathematical problem solving indicators. Third, can create mathematical models and solve problems from the tests given.

\section{CONCLUSION}

Based on the results of research and discussion on the stages of developing mathematical problems in the PISA model of Space and shape content to measure students' 
mathematical problem solving abilities, the following conclusions are obtained:

1. Mathematical problems in the PISA Model with Space and shape content developed as many as 5 items in the form of descriptions to measure students' mathematical problem solving abilities were declared valid. Valid based on the results of validation by experts because the five validators stated "the questions can be used with a little revision", with a reliability coefficient of 0.716 (high reliability)

2. Practicality of math problems The PISA model of Space and shape content to measure students' mathematical problem solving abilities can be used, this is based on expert assessments, teacher response questionnaires and student response questionnaires. The results of the teacher's questionnaire response of $83.33 \%$ are "very positive" to the questions that have been given, while the student responses of $75 \%$ are "positive" to the questions that have been given by the researcher. Mathematical problem solving ability of students in class IX-1 of private junior high school is concerned with mathematics problems. The PISA model of Space and shape content to measure students' mathematical problem solving abilities is obtained an average of 49.22 in the "medium" category.

\section{REFERENCES}

[1] Marbun, Merti Sanni P., Pargaulan Siagian., and Abil Mansyur. 2018. Development of Learning Devices Using Problem Based Learning Models to Improve Problem Solving Abilities Senior High School. Advances in Social Science, Education and Humanities Research(AISTEEL), volume 200.

[2] Hasratuddin. 2015. Why Should You Learn Mathematics?. Medan: Publishing Prime Publishing

[3] Ministry of National Education. 2006. Regulation of the Minister of National Education Number 22 of 2006 concerning Content Standards for Junior High Schools. Jakarta: Ministry of National Education.

[4] Permendikbud. 2013. Basic Framework and Curriculum Structure for Senior High School/Madrasah Aliyah, Jakarta: Minister of Education and Culture

[5] OECD. 2018. PISA 2015 PISA Results From PISA.

[6] OECD. 2019. PISA 2018 Result Combinate Executive Summaries Volune I, II, III.

[7] Wardhani, Sri. 2011. Instruments for Assessment of Junior High School Mathematics Learning Outcomes: Learning from PISA and TIMSS, Director General of Quality Improvement for Educators and Education Personnel, P4TK, Jogyakarta.
[8] Jurnaidi., and Zulkardi. 2017. Development of PISA Model Questions on Change and Relationship Content to Determine Mathematical Reasoning Ability of Junior High School Students. Journal of Mathematics Education. Volume 7 No 2

[9] Putra, Mulia and Rita Novita. 2015. Profile of Secondary School Student With High Mathematics Ability in Solving Shape and Space Problems. IndoMS-JME, Volume 6, No. 1, January 2015, pp. 20-30

[10] Carmila, N., Zulkardi., \& Darmawijoyo. (2016). The development of the PISA model of math problems using the Jambi context. Journal of Educational Research and Evaluation. 20 (2). 199207

[11] Saragih, Sahat., and Elvis Napitupulu. 2015.Developing Student-Centered Learning Model to Improve High Order Mathematical Thinking Ability.International Education Studies.Vol. 8, No. $6,104-112$.

[12] Surya, Eddy., Feria Andriana Daughter\& Mukhtar. 2017.Improving mathematical problem- solving. Journal on Mathematics ability and Self- confidence of high school students through Contextual learning model Education.Vol. 8 No. 1.Pp: 85-94

[13] Lubis, Reza Handika Winata, Edi Syahputra and Pargaulan Siagian. 2018. Improving Students Ability in Mathematical Problem Solving Through Problem Based Learning Model in Tenth Grades State Senior High School 7 of Medan. Advances in Social Science, Education and Humanities Research (AISTEEL), volume 200

[14] OECD. (2013). PISA 2012 assessment and analytical framework: mathematics, reading, science, problem solving and financial literacy. Paris: OECD Publishing.

[15] Stacey, Kaye. (2011). The PISA view of Mathematical literacy in Indonesia. IndoMS Journal Mathematics Education, 2(2), 95-126.

[16] Fatmawati, D and Ekawati, R. 2016. Development of PISA Math Problems Like on

[17] Suherman, E. (2003). Contemporary Mathematics Learning Strategy, rev.ed.. Bandung: JICA UPI.

[18] Nieveen, N. 1999. Prototyping to Reach Product Quality. In Jan Van den Akker, RM Branch, K. Gustafson, N. Nieveen \& Tj. Plomp (Eds). Design Approaches and Tools in Education and Training (pp125-135). Netherlands: Kluwer Academic Publishers.

[19] Aisha. 2013. Development of PISA Type Questions in Junior High Schools. Journal of Education. Volume 03. No. 01 